\title{
Rare occurrence of Hirayama disease in Brazil
}

\author{
Rara ocorrência da doença de Hirayama no Brasil \\ Mateos Bogoni', Bernardo Corrêa de Almeida Teixeira ${ }^{1}$, Marianna Cioni'
}

We present the case of a 17-year-old male with oblique unilateral hand and forearm amyotrophy, paresthesia and paresis. Tremor was present on finger extension. Hirayama disease was suspected, which led to dynamic cervical MRI. Hirayama disease affects predominantly young Asian males ${ }^{1,2}$, with few cases reported in the Americas ${ }^{3}$.
In this condition, underdevelopment of the spinal dura mater results in posterior dural detachment on the cervicothoracic region during flexion movements, which leads to asymmetric compression and ischemia of anterior horn cells ${ }^{4}$. The posterior venous plexus becomes engorged ${ }^{5}$, which is seen on dynamic MRI as a high T2 signal crescent in the posterior epidural space during flexion, with intense enhancement (Figures 1 and 2).
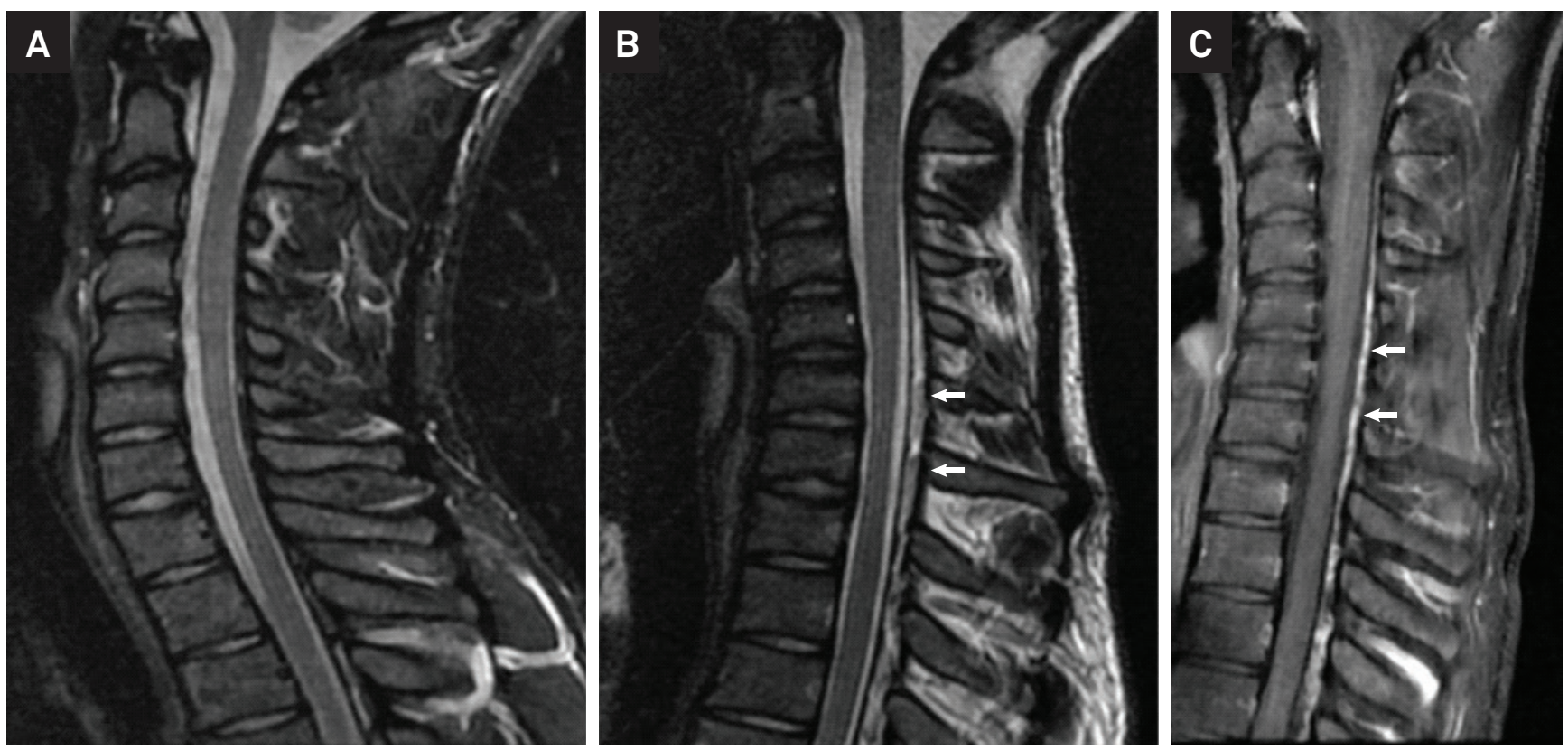

Figure 1. a) Sagittal STIR. Imaging in the neutral cervical position may appear inconspicuous at first; b) Sagittal T2 with cervical flexion. We notice detachment of the posterior dural layer, with reduction of the vertebral canal width and slight intramedullary hyperintensity. The engorged posterior vertebral venous plexus appears as a high signal crescent in the posterior epidural space (white arrows); c) Sagittal T1 Gd+ with cervical flexion. Uniform and intense enhancement of the posterior vertebral venous plexus is observed (white arrows).

${ }^{1}$ Universidade Federal do Paraná, Hospital de Clínicas, Departamento de Clínica Médica, Setor de Radiologia e Diagnóstico por Imagem, Curitiba PR, Brasil. Mateos Bogoni (iD) https://orcid.org/0000-0002-3892-3455

Correspondence: Mateos Bogoni; Universidade Federal do Paraná, Hospital de Clínicas; Rua General Carneiro, 181; 80060-900 Curitiba PR, Brasil; E-mail: bogonimateos@gmail.com

Conflict of interest: There is no conflict of interest to declare.

Received 06 December 2018; Received in final form 07 January 2019; Accepted 01 February 2019. 

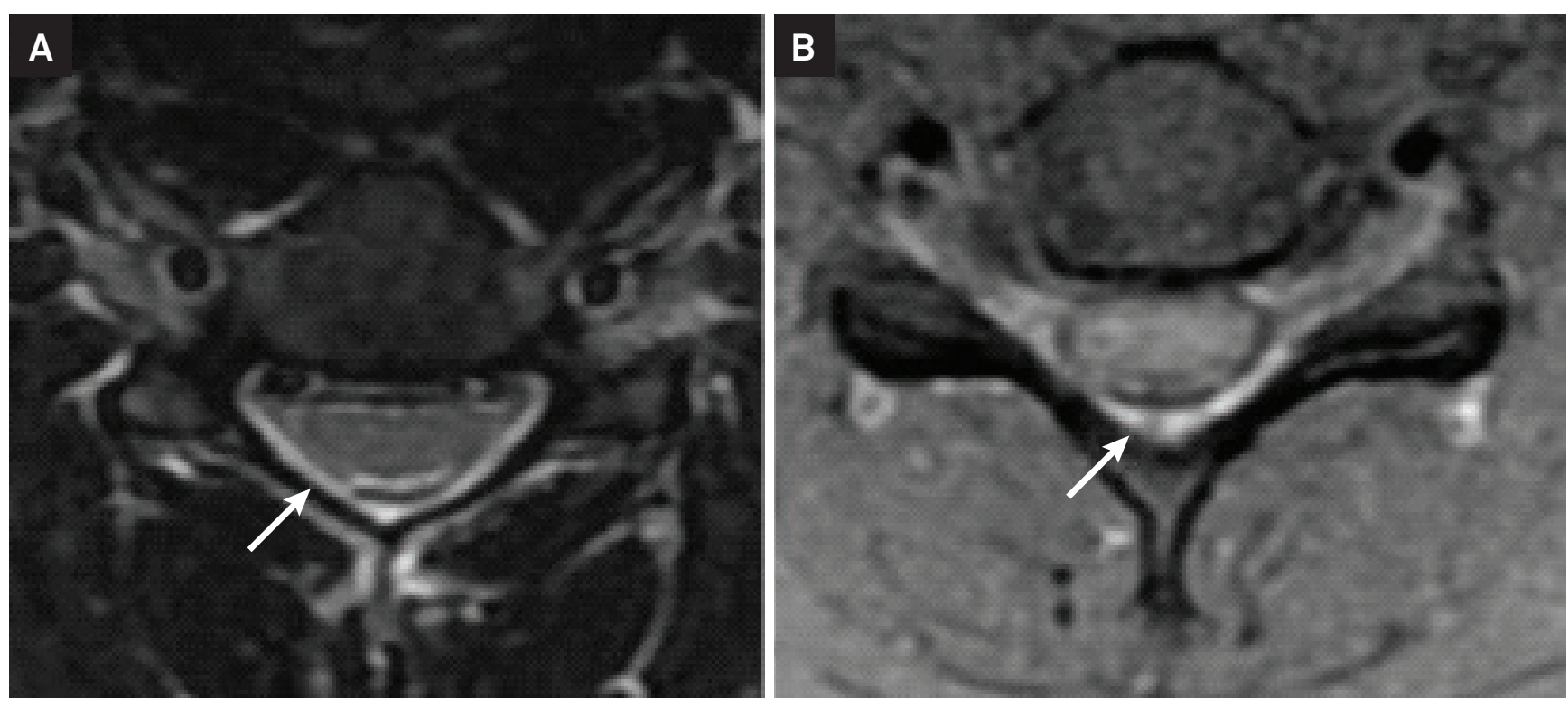

Figure 2. Axial T2 weighted (a) and T1 post-gadolinium (b) images show the posterior vertebral venous plexus (white arrows) in the epidural space during cervical flexion.

\section{References}

1. Hirayama K, Tsubaki T, Toyokura Y, Okinaka S. Juvenile muscular atrophy of unilateral upper extremity. Neurology. 1963 May;13(5):373-80. https://doi.org/10.1212/WNL.13.5.373

2. Gupta K, Sood S, Modi J, Gupta R. Imaging in Hirayama disease.J Neurosci Rural Pract. 2016 Jan-Mar;7(1):164-7. https://doi.org/10.4103/0976-3147.172174

3. Lehman VT, Luetmer PH, Sorenson EJ, Carter RE, Gupta V, Fletcher GP, et al. Cervical spine MR imaging findings of patients with Hirayama disease in North America: a multisite study. AJNR Am J Neuroradiol. 2013 Feb;34(2):451-6. https://doi.org/10.3174/ajnr.A3277

4. Toma S, Shiozawa Z. Amyotrophic cervical myelopathy in adolescence.J Neurol Neurosurg Psychiatry. 1995 Jan;58(1):56-64. https://doi.org/10.1136/jnnp.58.1.56

5. Hirayama K, Tokumaru Y. Cervical dural sac and spinal cord in juvenile muscular atrophy of distal upper extremity. Neurology. 2000 May;54(10):1922-6. https://doi.org/10.1212/WNL.54.10.1922 